\title{
A Review of Satellite Constraints on Airborne Dust: What We Can Say, and What We Can't
}

\author{
Ralph A. Kahn ${ }^{1 *}$ \\ ${ }^{1}$ NASA Goddard Space Flight Center, Greenbelt MD 2077 USA
}

\begin{abstract}
This is a review paper rather than the report on a single line of research. Satellites offer a broad range of constraints on dust particle amount, daily and longer-scale 3-d spatial distribution, particle properties, source locations, and transport pathways. Yet, the data contain spatial and temporal gaps, lack detail in some important respects, and interpretation of the remote-sensing retrieval results requires careful consideration of the information content, which can vary greatly with observing conditions. To date, these data have been applied much more extensively to dust from North African sources, and their journey across the Atlantic, than to Asian sources and Pacific transports, offering rich opportunities for future work.
\end{abstract}

\section{Introduction}

The earliest application of satellite observations to track dust transports dates back to the first days of satellite global reconnaissance of Earth; a dust plume emanating from the Sahara Desert was imaged traversing the Atlantic Ocean from June 5 - 12, 1967, with the videcon camera aboard the US Environmental Science and Services Administration's ESSA-5 satellite, deployed jointly by NASA and NOAA [1]. These observations brought into focus the global-scale nature of aerosol transports, and helped support subsequent investigation of tele-connections in general. Current-era satellites offer constraints on aerosol amount, 3-D spatial distribution, and transport. All require some assumptions, and the quality of the result can vary substantially with retrieval conditions. For dust transport in particular, distinguishing aerosol type is important. This has been currently done with lidar using the depolarization signal, with multi-angle imaging due to the flattening of the single-scattering phase function at side-scattering angles for non-spherical particles, and with multi-spectral imaging based on particle size. A lack of good optical models for different types of dust introduces significant uncertainties when deriving dust optical depth from radiance retrievals.

Nevertheless, when retrieval algorithms are applied at specific locations and seasons where dust dominates, and in some cases when the algorithms are tuned based on suborbital observations or case-study analyses, airborne dust layers can be mapped over extended regions. Satellite studies to date have favored dust transport from the Saharan region across the Atlantic Ocean, in part because aerosol type is easier to retrieve over ocean that over most land, in part because the Saharan region provides the largest single dust source globally, and in part because cloud contamination tends to interfere more with satellite aerosol remote sensing over the Pacific than the Atlantic. This leaves many opportunities to further exploit satellite data over land, and to explore the Asian dust transport across the Pacific. The current paper offers an overview of work from multiple groups, giving examples of the strengths and limitations of dust mapping from space-based observations, and illustrating where suborbital data and/or models have been used in conjunction with satellite data to provide a more complete picture.

\section{Retrieving Dust Particle Properties}

It has long been recognized that distinguishing generally large, non-spherical airborne mineral dust particles from other aerosol types is an essential step in mapping dust transports over large geographical regions with spacebased observations. Broad-swath, single-view multispectral instruments, such as the NASA Earth Observing System's (EOS) MODerate resolution Imaging Spectroradiometers (MODIS) offer extensive spatial coverage daily, and can provide some constraint on particle size, especially over dark water (e.g., [2]). The earliest idea aimed at using dust particle size as the distinguishing characteristic, and focused primarily in the visible spectral range. This approach required regionand season-specific tuning, to account for the smallparticle tail of the dust size distribution, and to avoid dominant contributions from other coarse-mode particles, such as ambient sea-salt [3,4]. Dust amount and plume height have been mapped with spectral data in the thermal infrared (IR) from the AIRS instrument, based on dust absorption around 10 microns, combined

\footnotetext{
* Corresponding author: ralph.a.kahn@
} 
with brightness temperature used to constrain elevation (e.g., [5]). As dust also absorbs in the ultraviolet (UV), dust occurrence, and some information about amount and elevation, can be retrieved, though with considerable assumptions [6,7], that can be mitigated if combined with data from other sources (e.g., [8,9]. Many of the key spacecraft instruments have relatively coarse spatial resolution (tens of kilometers) compared to the visible instruments, however, the IR and UV techniques have the advantage over the vis retrievals of similar sensitivity over land as over ocean, and the IR method can also collect data at night.

Where multi-angle data are acquired, such as from the NASA EOS Multi-angle Imaging SpectroRadiometer (MISR) instrument, particle shape can be deduced from distinct flattening of the single-scattering phase function at side-scattering angles for randomly oriented nonspherical particles, relative to spherical particles [10-14]. As mineral and soil dusts are the primary non-spherical particles in the atmosphere, this can provide a powerful diagnostic for regional dust-particle occurrence $[15,16]$. One challenge in applying this approach is separating dust from non-spherical cirrus [17]. And although the multi-angle, multi-spectral retrievals are more diagnostic of dust occurrence than the solely multi-spectral technique, MISR has global coverage only once in eight days near the equator, and every two days near the poles. In at least one study, the less frequent but more sensitive MISR dust identification was used to calibrate the MODIS dust detection scheme for the North Atlantic, after which the MODIS data were used to study the impact of the Madden-Julian Oscillation (MJO) on transAtlantic dust transport [18].

Non-spherical dust also has the property of depolarizing incident light, so multi-angle, multi-spectral polarized imagery has the potential to provide finer particle-type classification, under a broader range of retrieval conditions, than similar imagery lacking polarization sensitivity [19]. explored such data for the Polarization and Directionality of the Earth's Reflectances 3 (POLDER 3) polarimeter, but used only the retrieved real refractive index, single-scattering albedo, and the spectral dependence of extinction and absorption in the satellite analysis. The de-polarizing properties of non-spherical particles has been used directly to identify airborne mineral dust in lidar soundings with instruments such as the space-borne Cloud-Aerosol Lidar and Infrared Pathfinder Satellite Observations (CALIPSO) lidar, that includes polarization sensitivity [20]. Even early in the CALIPSO mission, the possibility of comprehensive dust mapping over the complex terrain of the Tibetan Plateau was demonstrated [21]. Advanced lidar instruments, so far deployed only aboard aircraft, have shown additional particle-type sensitivity, with fewer assumptions about intensive particle properties (e.g., [22,23]).
Among the assumptions required for remote-sensing retrievals is the need to specify dust particle optical properties, as distinct from those of other particle types. For multi-angle retrievals, the single-scattering phase function must be assumed; attempts to model this range from discrete-dipole simulations of complex shapes $[12,24]$ which are limited by compute power to small sizes and/or short wavelengths, semi-analytic efforts at simulating scattering by complex shapes (e.g., [25]), and simulations using aggregates of ellipsoids of varying aspect ratios $[11,26]$. The importance of obtaining accurate dust particle properties extends well beyond retrievals, to climate-related topics such as aerosol radiative forcing; satellite data figure heavily in such global questions (e.g., $[27,28])$. Yet, this remains an area of active research, as the simulations all have limitations for this application compared to real particles (e.g., [24]), and the collection and analysis of physical samples suffers from aircraft inlet limitations, required sampling volumes that exceed collection capabilities, and the enormous diversity of mineral dust types.

\section{Dust Sources and Transports}

The techniques described in Section 2 have been applied extensively to mapping dust source regions and transports. In particular, the advantage of UV and shortwave visible retrievals over land was exploited in mapping desert dust source regions in North Africa $[29,30]$. Dust plume location and motion vectors, derived from multi-angle radiance retrievals and geometric stereo mapping, respectively, have also been used to map dust sources in North Africa and the Middle East [31]. Among the limitations of these techniques is that large plumes of dust can obscure the actual source regions, especially as the temporal sampling of the observations is once daily (e.g., for MODIS), and less frequently for MISR. This is addressed in part with the SEVIRI geostationary instrument, measuring in the 8-12-micron thermal infrared; it can acquire data every 15-minutes, and observes generally lower dust opacity than measurements at shorter wavelengths $[32,33]$. For North Africa, the uv-visible and the IR approaches apparently provide greater sensitivity to different types of dust sources: shallow basins and complex terrain, respectively [33].

Satellite monitoring of dust transports tends to be more forgiving, compared to source characterization, with regard to temporal resolution and aerosol optical depth, but suffers from meteorological cloud obscuration, especially away from dry desert regions, and from the need to deduce advection and deposition from snapshot observations. Estimates of dust aerosol transport pathways [34] and fluxes have been made based on satellite snapshots alone (e.g., [35,36]). Aerosol forcing has also been estimated from a combination of aerosol optical depth, surface albedo, water vapor column amount, and shortwave and longwave top-of-atmosphere fluxes, all derived exclusively from satellite observations $[37 ; 38$ and references 
therein]. However, constraining a chemical transport model (CTM) with the 3-D aerosol spatial distribution and particle microphysical properties from multiple satellite instruments, as available, takes advantage of the meteorological fields and the spatial and temporal continuity of the model to credibly extrapolate the observations (e.g., [39]). Even limited satellite data, such as 2-d distribution snapshots of total aerosol and/or dust optical depth can provide powerful constraints on the parameterization and other assumptions in CTMs. These have been used to probe model dust transport performance on monthly, seasonal and inter-annual timescales, to test simulated dust vertical distribution, and to assess assumptions about mass-extinction efficiency [40-42].

\section{Future Prospects}

Much remains to be gleaned from satellite data already in hand, particularly over land, and over oceans other than the Atlantic. Satellite retrievals are likely to become somewhat more diagnostic of particle type once multiangle, multi-spectral, polarimetric imagery is applied more widely. In particular, it will probably increase retrieval sensitivity to the particle size distribution, and will offer some constraint on the real part of refractive index $[43,44]$, which could help identify dust from different sources. Having some space-based information about scattering-layer vertical distribution, e.g., from coincident UV or IR channels, could also help distinguish non-spherical dust from cirrus, especially over the tropical and subtropical oceans.

But there is also the need for in situ data from suborbital platforms. These are required to derive massextinction efficiency, required to translate between the broad-scale optical constraints offered by satellites with particle mass inherent to climate and air quality modeling, as well as to measure particle spectral lightabsorption properties at the precision required for climate-forcing calculations (e.g., [45]). And the use of aerosol transport models to better interpret and extend satellite dust observations is in its infancy; early work in this area suggests that the combination of observations and models will put source-attribution, aerosol transport amount and type, particle deposition, climate forcing, aerosol fertilization, and air quality assessment and prediction all on firmer ground.

The work of R. Kahn is supported in part by NASA Climate and Radiation Research and Analysis Program under Hal Maring, NASA Atmospheric Composition Program under Richard Eckman, and the NASA Earth Observing System MISR project.

\section{References}

1. J.M Prospero, E. Bonatti, C. Schubert, N.T. Carlson, T.N., Earth Planetary Science Letters 9, 287-293 (1970)
2. R.C. Levy, S. Mattoo, L.A. Munchak, L.A. Remer, A.M. Sayer, F. Patadia, and N.C. Hsu, Atmos. Meas. Tech. 6, 2989-3034, doi:10.5194/amt-6-2989-2013 (2013)

3. Y.J. Kaufman, I. Koren, L.A. Remer, D. Tanre', P. Ginoux, and S. Fan, J. Geophys. Res. 110, D10S12, doi:10.1029/2003JD004436 (2005)

4. H. Yu, L.A. Remer, M. Chin, H. Bian, R.G. Kleidman, and T. Diehl, J. Geophys. Res. 113, D14S12, doi:10.1029/2007JD009349 (2008)

5. S.G. DeSouza-Machado, et al., J. Geophys. Res. 115, D15201, doi:10.1029/2009JD012842 (2010)

6. J. Herman, P. Bhartia, O. Torres, C. Hsu, C. Seftor, and E. Celarier. J. Geophys. Res. 102, 16,911 16,922 (1997)

7. O. Torres, A. Tanskanen, B. Veihelman, C. Ahn, R. Braak, P.K. Bhartia, P. Veefkind, and P. Levelt, J. Geophys. Res. 112, D24S47, doi:10.1029/2007JD008809 (2007)

8. S.K. Satheesh, O. Torres, L. A. Remer, S. S. Babu, V. Vinoj, T. F. Eck, R. G. Kleidman, and B. N. Holben, J. Geophys. Res. 114, D05209, doi:10.1029/2008JD011024 (2009)

9. O. Torres, C. Ahn, and Z. Chen, Atmos. Meas. Tech. 6, 3257-3270, doi:10.5194/amt-6-3257-2013 (2013)

10. R.A. Kahn, R. West, D. McDonald, B. Rheingans, and M.I. Mishchenko, J. Geophys. Res. 102, 1686116870 (1997)

11. M.I. Mishchenko, L. Travis, R.A. Kahn, and R. West, J. Geophys. Res. 102, 16, 831-847 (1997)

12. O.V. Kalashnikova, R.A. Kahn, I.N. Sokolik, and W-H. Li, J. Geophys. Res. 110, doi: 10.1029/2004JD004550 (2005)

13. O.V. Kalashnikova and R.A. Kahn, J. Geophys. Res. 111, D11207, doi:10.1029/2005JD006756 (2006)

14. O.V. Kalashnikova, M.J. Garay, J.V. Martonchik, and D.J. Diner, Atmos. Meas. Tech. 6, 2131-2154, doi:10.5194/amt-6-2131-2013 (2013)

15. S. Dey, and L. Di Girolamo, J. Geophys. Res. 115, D15204, doi:10.1029/2009JD013395 (2010)

16. O.V. Kalashnikova and R.A. Kahn, J. Geophys. Res. 113, D24204, doi:10.1029/2008JD010083 (2008)

17. J.R. Pierce, R.A. Kahn, M.R. Davis, and J.M. Comstock, J. Geophys. Res. 115, D08201, doi:10.1029/2009JD013019 (2010)

18. Y. Guo, B. Tian, R.A. Kahn, O.V. Kalashnikova, S. Wong, and D.E. Waliser, J. Geophys. Res. 118, doi:10.1002/jgrd.50409 (2013)

19. P.B. Russell, et al., J. Geophys. Res. Atmos. 119, doi:10.1002/2013JD021411 (2014)

20. A.H. Omar, D.M. Winker, C. Kittaka, et al., J. Atm. Ocean Tech. 26,1994-2014 (2009)

21. Z. Liu, D. Liu, J. Huang, M. Vaughan, I. Uno, N. Sugimoto, C. Kittaka, C. Trepte, Z. Wang, C. Hostetler, and D. Winker, Atmos. Chem. Phys. 8, 
5045-5060, doi: www.atmos-chemphys.net/8/5045/2008 (2008)

22. S.P. Burton, R.A. Ferrare, C. Hostetler, et al., Atmos. Meas. Tech. 5, 73-98, doi:10.5194/amt-573-2012 (2012)

23. S.P. Burton, J.W. Hair, M. Kahnert, R.A. Ferrare, C.A. Hostetler, A. L. Cook, D. B. Harper, T. A. Berkoff, S.T. Seaman, J.E. Collins, M.A. Fenn, and R.R. Rogers, Atmos. Chem. Phys. 15, 13453-13473, doi:10.5194/acp-15-13453-2015 (2015)

24. H. Lindqvist, O. Jokinen, K. Kandler, D. Scheuvens, and T. Nousiainen, Atmos. Chem. Phys. 14, 143157, doi:10.5194/acp-14-143-2014 (2014)

25. L. Bi, P. Yang, G.W. Kattawar, and R.A. Kahn, Appl. Opt. 49, 334-342 (2010)

26. O. Dubovik, et al., J. Geophys. Res. 111, D11208, doi:10.1029/2005JD006619 (2006)

27. J.F. Kok, D.A. Ridley, Q. Zhou, R.L. Miller, C. Zhao, C.L. Heald, D.S.Ward, S. Albani, and K. Haustein, Nature Geosci., doi:10.1038/NGEO2912 (2017)

28. D.A. Ridley, C.L. Heald, J.F. Kok, and C. Zhao, Atmos. Chem. Phys. 16, 15097-15117, (2016)

29. J.M. Prospero, P. Ginoux, O. Torres, S. E. Nicholson, and T. E. Gill, Rev. Geophys., 40 (1), 1002, doi:10.1029/2000RG000095 (2002)

30. P. Ginoux, D. Garbuzov, and N. C. Hsu, J. Geophys. Res. 115, D05204, doi:10.1029/2009JD012398 (2010)

31. Y. Yu, Kalashnikova, O. V., Garay, M. J., Lee, H., and Notaro, M., Identification and characterization of dust source regions across North Africa and the Middle East using MISR satellite observations. Geophysical Research Letters 45, 6690-6701. https://doi.org/10.1029/2018GL078324 (2018)

32. A.T. Evan, S. Fiedler, C. Zhao, L. Menut, K. Schepanski, C. Flamant, and O. Doherty, Aeolian Research 16, 153-162. https://doi.org/10.1016/j.aeolia.2015.01.001 (2015)

33. K. Schepanski, I. Tegen, and A. Macke, Remote Sens. Environ. 123, 90-97 (2012)

34. J. Huang, C. Zhang, and J. M. Prospero, J. Geophys. Res. 115, D05202, doi:10.1029/2009JD012516 (2010a)

35. J. Huang, P. Minnis, H. Yan, Y. Yi, B. Chen, L. Zhang, and J.K. Ayers, Atmos. Chem. Phys., 10, 6863-6872, doi:10.5194/acp-10-6863-2010 (2010b)

36. H. Yu, M. Chin, H. Bian, T. Yuan, J.M. Prospero, A.H. Omar, L.A. Remer, D.M. Winker, Y. Yang, Y. Zhang, Z. Zhang, Remt. Sens. Env. 159 232-249, (2015)

37. S.A. Christopher and T. Jones, Geophys. Res., Lett. 34, L02810, doi:10.1029/2006GL027783 (2007)

38. E-S. Yang, P. Gupta, and S.A. Christopher, Geophys. Res. Lett. 36, L18812, doi:10.1029/2009GL039801 (2009)
39. H. Yu, L.A. Remer, R.A. Kahn, M. Chin, and Y. Zhang, Atmosph. Res. 124, 73-100 (2013)

40. D. Kim, et al., J. Geophys. Res. Atmos. 119, 62596277, doi:10.1002/2013JD021099 (2014)

41. D. Kim, et al., J. Geophys. Res. (to be submitted) (2018)

42. H. Yu, M. Chin, H. Bian, T. Yuan, J.M. Prospero, A.H. Omar, L.A. Remer, D.M. Winker, Y. Yang, Y. Zhang, Z. Zhang, Remt. Sens. Env. 159, 232-249, (2015)

43. O.P. Hasekamp and J. Landgraf, Appl. Opt. 46, 3332-3344 (2007)

44. M.I. Mishchenko and L.D. Travis, J. Geophys. Res. 102, 16989-17014 (1997)

45. R.A. Kahn, T. Berkoff, C. Brock, G. Chen, R. Ferrare, S. Ghan, T. Hansico, D. Hegg, J.V. Martins, C.S. McNaughton, D.M. Murphy, J.A. Ogren, J.E. Penner, P. Pilewskie, J. Seinfeld, and D. Worsnop, Bull. Am. Meteoro. Soc., 2215-2228, doi: 10.1175/BAMS-D-16-0003.1 (2017) 